\title{
CARACTERIZAÇÃO gUÍMICA DOS FRUTOS DE TRÊS MATRIZES DE ACEROLA (Malpighia emarginata D.C.) ${ }^{1}$
}

\author{
Vanusia Cavalcanti FRANÇA ${ }^{2, *}$, Narendra NARAIN ${ }^{3}$
}

\section{RESUMO}

A falta de classificação da acerola por classes varietais e a variabilidade de plantas, quanto ao porte, arquitetura da copa, coloração e forma dos frutos despertou o interesse quanto a sua caracterização química. Neste trabalho foram estudados frutos de três matrizes com características fisicas distintas, nos estádios de maturação "de vez" e "maduro" e em distintas safras. Observaram-se diferenças significativas através da análise ANOVA e teste de Tukey $(\mathrm{p} \leq 0,05)$, entre alguns parâmetros físicos (tamanho, peso), físico-químicos ( $\mathrm{pH}$ e sólidos solúveis), químicos (açúcares redutores e totais, ácido ascórbico e pectina).

Palavras-chave: acerola; Malpighia emarginata; açúcares redutores e totais; ácido ascórbico; pectina.
\end{abstract}

\section{SUMMARY}

CHEMICAL CHARACTERIZATION OF FRUITS OF THREE MATRICES OF ACEROLA (Malpighia emarginata D.C.). The lack of classification of acerola fruit in varietal classes and the variability of the plants regarding size, canopy architecture, color and shape of the fruits motivated the interest on its chemical characterization. In this work, fruits of three matrices of acerola with distinct physical characteristics regarding its maturation stages at different seasons, were studied. Significant differences were observed (p $\leq 0,05$ by Tukey), among some physical (size, weight), physico-chemical ( $\mathrm{pH}$ and soluble solids), and chemical (reducing and total sugars, ascorbic acid and pectin) parameters.

Keywords: acerola; Malpighia emarginata; reducing and total sugars; ascorbic acid; pectin.

\section{1 - INTRODUÇÃO}

O Brasil é o maior produtor mundial de acerola, sendo que na região Nordeste a área plantada é superior a 2.000 hectares. Na quase totalidade dos pomares instalados no Nordeste do Brasil observa-se uma mescla bastante acentuada de tipos e formas de aceroleiras, sendo comum encontrar-se, no mesmo pomar, plantas com hábitos de crescimento distinto, assim como frutos de formatos, coloração e tamanhos diferentes [8]. A necessidade de seleção das variedades, tem feito com que instituições desenvolvam pesquisas no sentido de caracterizar, selecionar e difundir plantas. Dessa forma, cada instituição tem adotado nomes ou códigos para identificar e diferenciar os frutos em função de seus genótipos.

NOGUEIRA [14] estudou as matrizes utilizadas neste trabalho, denominando-as UFRPE 7, UFRPE 8 e UFRPE 20. Os diferentes aspectos físicos dos frutos das citadas matrizes, tais como: tamanho, formato e cor, despertaram o interesse quanto a sua caracterização química.

O estudo dos frutos das matrizes UFRPE 7, UFRPE 8 e UFRPE 20 em três safras distintas e nos estádios de maturação "de vez" e "maduro", foi o objetivo deste trabalho, visando contribuir para sua classificação física e química.

\footnotetext{
Recebido para publicação em 24/05/2001. Aceito para publicação em 02/09/2002. Parte da dissertação de Mestrado apresentada ao CPCTA-UFPB (000661).

${ }^{2}$ E-mail:vanusiafranca@bol.com.br.

${ }^{3}$ Departamento de Tecnologia Química e de Alimentos (DTQA/CT/UFPB) Campus I, João Pessoa-PB, 58.059-900 - Brasil

* A quem a correspondência deve ser enviada.
}

\section{2 - MATERIAL E MÉTODOS}

\section{1 - Material}

Foram utilizados frutos provenientes do pomar comercial Acerolândia, situado no municipio de Paudalho, Zona da Mata do Estado de Pernambuco. O local possui clima quente e úmido com temperatura média anual de $25^{\circ} \mathrm{C}$, precipitação pluviométrica média anual de $1.700 \mathrm{~mm}$ e período de chuvas nos meses de março a julho. A época de coleta dos frutos e as condições climáticas no local estão representadas no Quadro 1.

QUADRO 1. Condições climáticas e época de coleta dos frutos de acerola (Malpighia emarginata D. C.).

\begin{tabular}{|cccc|}
\hline Safra & Época & $\begin{array}{c}\text { Temperatura média } \\
{ }^{\circ} \mathrm{C}\end{array}$ & $\begin{array}{c}\text { Precipitação pluviométrica } \\
\mathrm{mm}\end{array}$ \\
\hline I & Agosto de 1997 & 23,6 & 72,5 \\
II & Novembro de 1997 & 27,0 & 8,2 \\
III & Maio de 1998 & 26,2 & 154,5 \\
\hline
\end{tabular}

Para a classificação dos frutos quanto aos estádios de maturação, foi utilizado o grau de coloração da casca e considerados frutos "de vez", aqueles que apresentavam $70 \%$ da casca com coloração amarela, laranja, vermelha ou roxa e frutos "maduros" aqueles que apresentavam $100 \%$ da casca com coloração amarela, laranja, vermelha ou roxa. Quanto ao aspecto físico dos frutos, observaram-se diferenças marcantes na morfologia entre as matrizes, sendo UFRPE 8 (pitanga), UFRPE 20 (maçã ovalada) e UFRPE 7 (maçã trilobada), mostradas na Figura 1. Os frutos foram separados em 5 lotes, cada um pesando cerca de $200 \mathrm{~g}$, tendo as análises físicas sido 
realizadas em 5 frutos por lote, escolhidos aleatoriamente. As análises físico-químicas e químicas foram realizadas em duplicata a partir da polpa obtida separadamente de cada lote. Os frutos das matrizes UFRPE 7 e UFRPE 8 foram coletados nas três safras, mas aqueles da matriz UFRPE 20 foram coletados apenas na safra II, devido ao fato de somente nessa safra seu ciclo reprodutivo ocorrer simultaneamente com os demais.

\section{2 - Local de execução}

O presente trabalho foi desenvolvido nos laboratórios de Bioquímica de Alimentos do Departamento de Tecnologia de Alimentos no Centro de Tecnologia - UFPB.

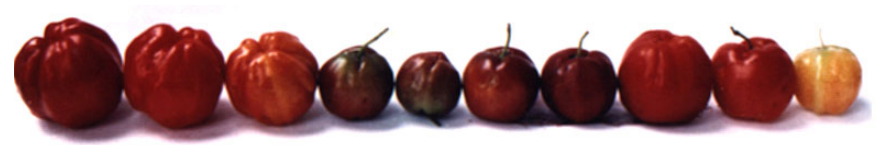

FIGURA 1. Frutos das matrizes estudadas. Da esquerda para a direita: 3 frutos UFRPE 8; 4 frutos UFRPE 20 e 3 frutos UFRPE 7.

\section{3 - Métodos}

As análises de determinação de $\mathrm{pH}$, sólidos solúveis, cinzas e cálcio seguiram métodos do INSTITUTO ADOLFO LUTZ [11] e as análises de acidez titulável, umidade, ácido ascórbico, pectina, ferro e fósforo seguiram métodos descritos por RANGANNA [16]. A determinação de açúcares redutores e totais foi feita pelo método de Lane \& Eynon, descrito também em RANGANNA [16] e a de ácido ascórbico sofreu modificação no método pela substituição do ácido metafosfórico pelo ácido oxálico.

Foi utilizado o programa de software SPSS ("Statistical Package for the Social Science") for Windows - Release 6.0.1 e a comparação das médias foi realizada pelo teste de Tukey, a 5\% de probabilidade.

\section{3 - RESULTADOS E DISCUSSÃO}

As determinações físicas mostraram durante a evolução do processo de maturação, aumento nos valores de peso, altura e diâmetro, do estádio de maturação "de vez" para o "maduro". Esses resultados estão de acordo com a literatura $[1,4,9,13,14]$. Na Tabela 1 observa-se que os frutos da matriz UFRPE 20 apresentaram menores pesos e dimensões.

Na Tabela 2 o aumento no valor do pH do estádio "de vez" para o "maduro" é indicativo da diminuição de acidez dos frutos à medida que ocorreu a maturação, independentemente da matriz. Nota-se ainda que houve um aumento gradual nos valores de $\mathrm{pH}$ ao longo das safras, indicando que na safra III (inverno) os frutos apresentaram-se menos ácidos que na safra I (verão). Sólidos solúveis apresentaram aumento de valores do estádio de maturação "de vez" para o "maduro", tendo os frutos da matriz UFRPE 20 apresentado valores menores e significativamente diferentes dos demais. O elevado valor en- contrado para acidez titulável é devido a esta fruta ser rica em ácidos orgânicos, tendo CARVALHO \& MANICA [3] encontrado valores ainda maiores (1,65 e 1,63\%). Sapoti apresenta valor de 0,26\% [2] para acidez titulável e maracujá 0,49 a 0,39\% [5].

TABELA 1. Média dos valores das determinações físicas (peso, altura e diâmetro) de frutos de matrizes de acerola em diferentes estádios de maturação e safras.

\begin{tabular}{|c|c|c|c|c|c|c|c|}
\hline \multirow[t]{2}{*}{ Matriz } & \multirow[t]{2}{*}{ Safra } & \multicolumn{2}{|c|}{ Peso (g) } & \multicolumn{2}{|c|}{ Altura $(\mathrm{cm})$} & \multicolumn{2}{|c|}{ Diâmetro $(\mathrm{cm})$} \\
\hline & & $" 1 "$ & “2” & $" 1 "$ & "2" & "1" & "2" \\
\hline \multirow[t]{3}{*}{ UFRPE 7} & I & $7,87^{\mathrm{Aa}}$ & $10,04^{\mathrm{Aa}}$ & $1,98^{\mathrm{Aa}}$ & $2,29^{\mathrm{Aa}}$ & $2,35^{\mathrm{Aa}}$ & $2,67^{\mathrm{Aa}}$ \\
\hline & II & $9,60^{\text {Aab }}$ & $10,71^{\mathrm{Aa}}$ & $2,22^{\mathrm{Aa}}$ & 2,31 Aa & $2,65^{\text {Aab }}$ & $2,74^{\mathrm{Aa}}$ \\
\hline & III & $10,30^{\mathrm{Ab}}$ & $10,05^{\mathrm{Aa}}$ & $2,06^{\mathrm{Aa}}$ & $2,21^{\mathrm{Aa}}$ & $2,71^{\mathrm{Ab}}$ & $2,75^{\mathrm{Aa}}$ \\
\hline \multirow[t]{3}{*}{ UFRPE 8} & I & $9,06^{\text {Aa }}$ & $10,85^{\mathrm{Aa}}$ & $2,19^{\mathrm{Aa}}$ & $2,34^{\mathrm{Aa}}$ & $2,68 \mathrm{Aa}$ & $2,83^{\mathrm{Aa}}$ \\
\hline & II & $7,51^{\mathrm{Bb}}$ & $9,70^{\mathrm{Aa}}$ & 2,21 Aa & $2,35^{\text {Aab }}$ & $2,32^{\mathrm{Ab}}$ & $2,68^{\mathrm{Aa}}$ \\
\hline & III & $8,50^{\mathrm{Bab}}$ & $9,54^{\text {Aa }}$ & $2,25^{\mathrm{Aa}}$ & $2,21^{\mathrm{Aa}}$ & $2,59^{\mathrm{Aab}}$ & $2,75^{\mathrm{Aa}}$ \\
\hline UFRPE 20 & II & $1,96^{\mathrm{C}}$ & $2,65^{\mathrm{B}}$ & $1,37^{\mathrm{B}}$ & $1,43^{\mathrm{B}}$ & $1,46^{\mathrm{B}}$ & $1,62^{\mathrm{B}}$ \\
\hline
\end{tabular}

Estádios de maturação: "1" de vez; "2" maduro. Letras maiúsculas comparam médias entre matrizes e minúsculas comparam médias entre safras para uma mesma matriz. Letras diferentes diferem significativamente, de acordo com o teste de Tukey,

a nivel de $5 \%$ de probabilidade.
Os dados representam a média de 25 repetições.

Segundo SALUNKHE E DESAI [18], a acerola apresenta entre seus açúcares, glicose e frutose, e quantidades minimas de sacarose. Os frutos no estádio de maturação "maduro" apresentaram maiores teores que os "de vez" com pequena diferença entre açúcares redutores e totais, sendo os redutores em maior quantidade. Os valores encontrados (Tabela 3) estão de acordo com DIÓGENES NOGUEIRA [7] 2,84 a 3,94\%, PIMENTEL [15] 3,57\% e GORGATTI NETO et al. [9] 2,34 a 4,84\%.

TABELA 2. Média dos valores das determinações fĩsico-químicas ( $\mathrm{pH}$ e sólidos solúveis) e química (acidez titulável) de matrizes de acerola em diferentes estádios de maturação e safras.

\begin{tabular}{|c|c|c|c|c|c|c|c|c|c|}
\hline \multirow[t]{2}{*}{ Matriz } & \multirow[t]{2}{*}{ Safra } & \multicolumn{2}{|c|}{$\mathrm{pH}$} & \multicolumn{2}{|c|}{$\begin{array}{c}\text { Sólidos solúveis } \\
\text { ( }{ }^{\circ} \text { Brix) }\end{array}$} & \multicolumn{2}{|c|}{$\begin{array}{l}\text { Acidez titulável } \\
\text { (\% ácido cítrico) }\end{array}$} & \multicolumn{2}{|c|}{$\begin{array}{c}{ }^{\circ} \text { Brix/Acidez } \\
\text { titulável }\end{array}$} \\
\hline & & $" 1 "$ & "2" & "1" & "2" & $" 1 "$ & "2" & "1" & "2" \\
\hline \multirow[t]{3}{*}{ UFRPE 7} & I & $3,12^{\mathrm{Aa}}$ & $3,18^{\mathrm{Aa}}$ & $6,0^{\mathrm{Aa}}$ & $6,1^{\mathrm{Aat}}$ & $1,38^{\mathrm{Aa}}$ & $1,30^{\mathrm{Aa}}$ & $4,35^{\mathrm{Aa}}$ & $4,73^{\mathrm{Aa}^{2}}$ \\
\hline & II & $3,14^{\mathrm{Aa}}$ & $3,23^{\mathrm{Ab}}$ & $6,0^{\mathrm{Aa}}$ & $6,3^{\mathrm{Aa}}$ & $1,15^{\mathrm{Ab}}$ & $1,09^{\mathrm{Ab}}$ & $5,25^{\mathrm{Ab}}$ & $5,8^{\mathrm{Ab}}$ \\
\hline & III & $3,43^{\mathrm{Ab}}$ & $3,53^{\mathrm{Ac}}$ & $6,1^{\text {Aa }}$ & $6,5^{\mathrm{Ab}}$ & $1,09^{\mathrm{Ab}}$ & $0,98^{\mathrm{Ab}}$ & $7,82^{\mathrm{Ac}}$ & $9,42^{\mathrm{Ac}}$ \\
\hline \multirow[t]{3}{*}{ UFRPE 8} & I & $3,18^{\mathrm{Ba}}$ & $3,24^{\mathrm{Ba}}$ & $6,1^{\text {Aa }}$ & $6,1^{\mathrm{Aa}}$ & $1,11^{\mathrm{Ba}}$ & $1,12^{\mathrm{Ba}}$ & $5,48^{\mathrm{Ba}}$ & $5,48^{\mathrm{Ba}}$ \\
\hline & II & $3,25^{\mathrm{Bb}}$ & $3,30^{\mathrm{Bb}}$ & $6,1^{\mathrm{Aa}}$ & $6,4^{\mathrm{Ab}}$ & $1,15^{\mathrm{Aa}}$ & $0,96^{\mathrm{Bb}}$ & $5,36^{\mathrm{Aa}}$ & $6,63^{\mathrm{Bb}}$ \\
\hline & III & $3,28^{\mathrm{Bb}}$ & $3,40^{\mathrm{Bc}}$ & $6,2^{\text {Aa }}$ & $6,4^{\mathrm{Ab}}$ & $1,29^{\mathrm{Bb}}$ & $1,12^{\mathrm{Ba}}$ & $4,78^{\mathrm{Bb}}$ & $5,68^{\mathrm{Ba}}$ \\
\hline UFRPE 20 & II & $3,35^{\mathrm{C}}$ & $3,31^{B}$ & $5,4^{\mathrm{B}}$ & $5,7^{B}$ & $1,02^{\mathrm{B}}$ & $0,93^{B}$ & $5,30^{A}$ & $6,14^{\mathrm{A}}$ \\
\hline
\end{tabular}

Estádios de maturação: "1" de vez; "2" maduro. Letras maiúsculas comparam médias entre matrizes e minúsculas comparam médias entre safras para uma mesma matriz. Letras diferentes diferem significativamente, de acordo com o tes-

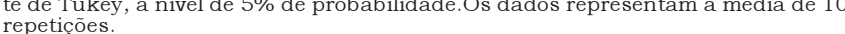


Pectina aparentemente sofreu influência das safras, pois apresentou queda nos valores para a safra II (verão), para as três matrizes e nos diferentes estádios de maturação. Observou-se também queda desses valores do estádio de maturação "de vez" para o "maduro", conforme era esperado e de acordo com a literatura $[1,6$, $10,12]$.

TABELA 3. Média dos valores das determinações químicas de matrizes de acerola em diferentes estádios de maturação e safras.

\begin{tabular}{|c|c|c|c|c|c|c|c|}
\hline \multirow[t]{2}{*}{ Determinação } & \multirow[t]{2}{*}{ Safra } & \multicolumn{2}{|c|}{ UFRPE 7} & \multicolumn{2}{|c|}{ UFRPE 8} & \multicolumn{2}{|c|}{ UFRPE 20} \\
\hline & & "1" & "2" & $" 1 "$ & "2" & "1" & "2" \\
\hline Umidade & I & $92,00^{\text {Aa }}$ & $91,97^{\mathrm{Aa}}$ & $93,05^{\mathrm{Ba}}$ & $92,88^{\mathrm{Ba}}$ & & \\
\hline \multirow[t]{2}{*}{$(\% \mathrm{p} / \mathrm{p})$} & II & $92,65^{\mathrm{Ab}}$ & $92,48^{\text {Aab }}$ & $92,59^{\mathrm{Ab}}$ & $92,14^{\mathrm{Ab}}$ & $93,46^{\mathrm{B}}$ & $93,53^{\mathrm{B}}$ \\
\hline & III & $92,44^{\text {Aab }}$ & $92,60^{\mathrm{Ab}}$ & $92,21^{\mathrm{Ab}}$ & $92,43^{\mathrm{Aa}}$ & & \\
\hline Açúcar & I & $3,04^{\mathrm{Aa}}$ & $3,55^{\mathrm{Aa}}$ & $3,18^{\mathrm{Ba}}$ & $3,57^{\mathrm{Aa}}$ & & \\
\hline Redutor & II & $3,15^{\mathrm{Ab}}$ & $3,67^{\mathrm{Aa}}$ & $3,28^{\mathrm{Aa}}$ & $3,59^{\mathrm{Aa}}$ & $3,31^{\mathrm{A}}$ & $3,53^{\mathrm{A}}$ \\
\hline$(\% \mathrm{p} / \mathrm{p})$ & III & $3,35^{\mathrm{Ac}}$ & $4,00^{\mathrm{Ab}}$ & $3,39^{\mathrm{Aa}}$ & $3,66^{\mathrm{Ba}}$ & & \\
\hline Açúcar Total & I & $3,64^{\mathrm{Aa}}$ & $4,26^{\mathrm{Aa}}$ & $3,87^{\mathrm{Aa}}$ & $4,19^{\mathrm{Aa}}$ & & \\
\hline \multirow[t]{2}{*}{$(\% \mathrm{p} / \mathrm{p})$} & II & $3,75^{\mathrm{Aa}}$ & $4,42^{\text {Aab }}$ & $4,05^{\mathrm{Aa}}$ & $4,21^{\mathrm{Aa}}$ & $3,82^{\mathrm{A}}$ & $4,25^{\mathrm{A}}$ \\
\hline & III & $3,80^{\mathrm{Aa}}$ & $4,61^{\mathrm{Ab}}$ & $4,09^{\mathrm{Ba}}$ & $4,26^{\mathrm{Ba}}$ & & \\
\hline Pectina & I & $1,37^{\mathrm{Aa}}$ & $1,15^{\mathrm{Aa}}$ & $0,99^{\mathrm{Ba}}$ & $0,84^{\mathrm{Ba}}$ & & \\
\hline \multirow[t]{2}{*}{$(\% \mathrm{p} / \mathrm{p})$} & II & $0,97^{\mathrm{Ab}}$ & $0,83^{\mathrm{Ab}}$ & $0,93^{\mathrm{Aa}}$ & $0,78^{\mathrm{Bb}}$ & $0,87^{\mathrm{B}}$ & $0,73^{\mathrm{C}}$ \\
\hline & III & $1,20^{\mathrm{Ac}}$ & $1,01^{\mathrm{Ac}}$ & $1,36^{\mathrm{Bb}}$ & $1,20^{\mathrm{Bc}}$ & & \\
\hline Ácido & I & $2,34^{\mathrm{Aa}}$ & $1,76^{\mathrm{Aa}}$ & $1,60^{\mathrm{Ba}}$ & $1,48^{\mathrm{Ba}}$ & & \\
\hline Ascórbico & II & $1,50^{\mathrm{Ab}}$ & $1,22^{\mathrm{Ab}}$ & $1,57^{\mathrm{Aa}}$ & $1,16^{\mathrm{Ab}}$ & $1,22^{\mathrm{B}}$ & $0,94^{\mathrm{B}}$ \\
\hline$(\% \mathrm{p} / \mathrm{p})$ & III & $2,08^{\mathrm{Ac}}$ & $1,51^{\mathrm{Ac}}$ & $2,72^{\mathrm{Bb}}$ & $2,00^{\mathrm{Bc}}$ & & \\
\hline Cinzas & I & $0,34^{\mathrm{Aa}}$ & $0,34^{\mathrm{Aa}}$ & $0,35^{\mathrm{Aa}}$ & $0,35^{\mathrm{Aa}}$ & & \\
\hline \multirow[t]{2}{*}{$(\% \mathrm{p} / \mathrm{p})$} & II & $0,34^{\mathrm{Aa}}$ & $0,34^{\mathrm{Aa}}$ & $0,35^{\text {Aa }}$ & $0,34^{\mathrm{Aa}}$ & $0,36^{\mathrm{A}}$ & $0,37^{\mathrm{A}}$ \\
\hline & III & $0,33^{\mathrm{Aa}}$ & $0,33^{\mathrm{Aa}}$ & $0,34^{\mathrm{Aa}}$ & $0,34^{\mathrm{Aa}}$ & & \\
\hline
\end{tabular}

Estádios de maturação: "1" de vez; "2" maduro. Letras maiúsculas comparam médias entre matrizes e minúsculas comparam médias entre safras para uma mesma matriz. Letras diferentes diferem significativamente, de acordo com o teste de Tukey,

a nivel de $5 \%$ de probabilidade.
Os dados representam a média de 10 repetições.

Frutos "de vez" apresentaram maiores valores de ácido ascórbico que os "maduros", independentemente da matriz, estando esse fato de acordo com a literatura $[14,17,18]$. As safras não exerceram influência igual para as matrizes, pois foram observados maiores teores de ácido ascórbico na safra I para a matriz UFRPE 7, e na safra III para a UFRPE 8. No entanto, a safra II (verão) indicou menores teores para essas duas matrizes. UFRPE 20 apresentou diferença significativa a 5\% em relação às demais matrizes.

Os teores de cinzas não apresentaram diferenças significativas entre as matrizes e os diferentes estádios de maturação.

Os resultados das determinações de cálcio, fósforo e ferro estão na Tabela 4.

Observaram-se diferenças significativas a $5 \%$ de probabilidade entre as três matrizes e os diferentes estádios de maturação, nas diferentes safras analisadas, para os minerais cálcio e fósforo. As análises de ferro indicaram apenas traços desse elemento, uma vez que as leituras ficaram fora da margem de segurança da curva padrão ou não foram sequer detectadas, mesmo quando utilizaram-se quantidades maiores de polpa para obtenção de cinzas. Sabe-se que os minerais presentes nas frutas sofrem influências de alguns fatores, entre eles a adubação, que é aplicada de maneira e quantidades irregulares no pomar onde foram coletados os frutos analisados no presente trabalho. Assim sendo, não foi possivel estabelecer correlações entre essas determinações e os diferentes parâmetros analisados.

TABELA 4. Média dos valores das determinações de cálcio, fósforo e ferro de matrizes de acerola em diferentes estádios de maturação e safras.

\begin{tabular}{|c|c|c|c|c|c|c|c|}
\hline \multirow[t]{3}{*}{ Matriz } & \multirow[t]{3}{*}{ Safra } & \multicolumn{2}{|c|}{ Cálcio } & \multicolumn{2}{|c|}{ Fósforo } & \multicolumn{2}{|c|}{ Ferro } \\
\hline & & \multicolumn{2}{|c|}{ (mg/100g de polpa) } & \multicolumn{2}{|c|}{ (mg/100g de polpa) } & \multicolumn{2}{|c|}{ (mg/100g de polpa) } \\
\hline & & "1" & "2" & "1" & "2" & "1" & "2" \\
\hline \multirow[t]{3}{*}{ UFRPE 7} & I & $32,05^{\mathrm{Aa}}$ & $29,92^{\mathrm{Aa}}$ & $4,86^{\mathrm{Aa}}$ & $8,23^{\mathrm{Aa}}$ & traços & traços \\
\hline & II & $28,44^{\mathrm{Ab}}$ & $32,08^{\mathrm{Aa}}$ & $11,54^{\mathrm{Ab}}$ & $26,00^{\mathrm{Ab}}$ & ND & ND \\
\hline & II & $44,08^{\mathrm{Ac}}$ & $41,83^{\mathrm{Ab}}$ & $60,12^{\mathrm{Ac}}$ & $53,12^{\mathrm{Ac}}$ & traços & traços \\
\hline \multirow[t]{3}{*}{ UFRPE 8} & I & $57,64^{\mathrm{Ba}}$ & $55,60^{\mathrm{Ba}}$ & $12,83^{\mathrm{Ba}}$ & $12,89^{\mathrm{Ba}}$ & traços & traços \\
\hline & II & $23,88^{\mathrm{Bb}}$ & $24,46^{\mathrm{Bb}}$ & $21,95^{\mathrm{Bb}}$ & $22,58^{\mathrm{Bb}}$ & ND & ND \\
\hline & III & $55,34^{\mathrm{Bc}}$ & $47,21^{\mathrm{Bc}}$ & $27,87^{\mathrm{Bc}}$ & $29,58^{\mathrm{Bc}}$ & traços & traços \\
\hline UFRPE 20 & II & $54,20^{\mathrm{C}}$ & $41,24^{C}$ & $11,13^{\mathrm{C}}$ & $16,87^{\mathrm{C}}$ & ND & ND \\
\hline
\end{tabular}

Estádios de maturação: "1" de vez; "2" maduro. ND = não detectado. Letras maiúsculas comparam médias entre matrizes e minúsculas comparam médias entre safras para uma mesma matriz. Letras diferentes diferem significativamente, de acordo com o teste de Tukey, a nivel de $5 \%$ de probabilidade.
Os dados representam a média de 10 repetições.

\section{4 - CONCLUSÕES}

A caracterização das matrizes revelou diferenças significativas em vários parâmetros, em especial nos teores de ácido ascórbico, açúcares e pectina, de grande importância para as indústrias de processamento de alimentos (sucos e doces) e farmacêuticas (vitamina C). Esta conclusão sugere a necessidade de uma escolha mais criteriosa no cultivo de determinadas matrizes por parte dos produtores, à medida que irá agregar valores econômicos na venda dos frutos às indústrias, de acordo com o parâmetro desejado.

\section{5 - REFERÊNCIAS}

[1] AWAD, M. Fisiologia Pós-Colheita de Frutas. São Paulo: Nobel, 1993.

[2] BRITO, E. S. Estudo sobre Constituintes Voláteis e Fisiologia Pós-Colheita da Sapota (Manilkara zapota L. P. Royen). João Pessoa, 1993, 107p. Dissertação de Mestrado. UFPB.

[3] CARVALHO, R. I. N.; MANICA, I. Influência de estádios de maturação e condições de armazenamento na conservação da acerola (Malpighia glabra L.). Pesquisa Agropecuária Brasileira, Brasília, v.29, n.5, p.681$688,1994$.

[4] CHITARRA, M. I. F. Colheita e qualidade pós-colheita de frutos. Informativo Agrícola. Belo Horizonte, v. 17, n. 179, p.8-18, 1994. 
[5] CORRÊA, R. M. Identificação de Constituintes Voláteis e Fisiologia Pós-Colheita do Maracujá (Passiflora edulis forma Flavicarpa). Dissertação de Mestrado. UFPB. João Pessoa, 1995. 112p.

[6] CRUESS, W. V. Produtos Industriais de Frutas e Hortaliças. São Paulo: Ed. Blucher, 1973.

[7] DIÓGENES NOGUEIRA, C. M. C. Estudo Químico e Tecnológico da Acerola (Malpighia glabra L.). Fortaleza, 1991. 147p. Dissertação de Mestrado. UFC.

[8] GONZAGA NETO, L.; SOARES, J. M. Acerola para Exportação: Aspectos Técnicos da Produção. Coleção FRUPEX. Brasília: EMBRAPA-SPI, 1994. 43p.

[9] GORGATTI NETO, A.; ARDITO, E. F. G.; GARCIA, E. E. C. et al. Acerola para Exportação: Procedimentos de Colheita e Pós-Colheita. Coleção FRUPEX. Brasília: EMBRAPA-SPI, 1996. 30p.

[10] HELENA, M. L. F. Geléias. Manuais práticos - VIDA. São Paulo: Ed. Três Ltda. 1985. 32p.

[11] INSTITUTO ADOLFO LUTZ. Normas Analíticas do Inst. Adolfo Lutz. São Paulo: Instituto Adolfo Lutz, 1976.

[12] JACKIX, M. H. Doces, geléias e frutas em calda. Coleção Ciência e Tecnologia ao alcance de todos: Série Tecnologia de Alimentos. Campinas: Ícone, 1988. 172p.
[13] MARINO NETO, L. Acerola, a cereja tropical. São Paulo: Nobel, 1986. 94p.

[14] NOGUEIRA, R. J. M. Expressões Fisiológicas da Aceroleira (Malpighia emarginata D. C.) em Condições Adversas. São Carlos, 1997. 207p. Tese de Doutorado. UFSCar.

[15] PIMENTEL, M. L. Influência do Processamento sobre a Vit.C do suco de Acerola (Malpighia glabra L.). Fortaleza, 1996. 83p. Dissertação de Mestrado. UFC.

[16] RANGANNA, S. Handbook of Analysis and Quality Control for Fruit and Vegetable Products. New Delhi: McGrawHill, 1979.

[17] ROCHA, I. C. Suco de Acerola: Efeito da Temperatura de Pasteurização e Armazenamento. Recife, 1988. 62p. Dissertação de Mestrado. UFPE.

[18] SAlunkhe, D. K. \& DESAI, B. B. Posthakvest biotechnology of Fruits. Flórida: CRC, 1984. v.2, cap.13.

\section{6 - AGRADECIMENTOS}

Os autores agradecem ao Sr. Alcindo Lacerda, proprietário do pomar Acerolândia - Paudalho -PE, pela doação da matéria-prima e ao $\mathrm{CNPq}$ pelo apoio financeiro em forma de bolsa à mestranda. 